\title{
Lysergic acid diethylamide-associated intoxication in Hong Kong: a case series
}

\author{
C Li ${ }^{1,2}$, MB, BS, Magdalene HY Tang ${ }^{1}$, PhD, YK Chong ${ }^{1,2}$, FHKCPath, FHKAM (Pathology), Tina YC Chan ${ }^{1,2}$, MB, ChB, PhD, \\ Tony WL Mak ${ }^{1,2 *}$, FRCPath, FHKAM (Pathology) \\ ${ }^{1}$ Hospital Authority Toxicology Reference Laboratory, Hong Kong \\ ${ }^{2}$ Chemical Pathology Laboratory, Department of Pathology, Princess Margaret Hospital, Laichikok, Hong Kong \\ *Corresponding author: makwl@ha.org.hk \\ Hong Kong Med J 2019;25:323-5 \\ https://doi.org/10.12809/hkmj197942
}

\section{Case series}

Lysergic acid diethylamide (LSD) is a powerful hallucinogenic drug that was first synthesised in 1938. ${ }^{1}$ Although LSD is considered a conventional drug of abuse, cases of LSD intoxication are scarce in Hong Kong. The Hospital Authority Toxicology Reference Laboratory-the only tertiary referral laboratory for toxicological analysis in Hong Kong, established in 2004-did not encounter cases of LSD intoxication until 2015. Between 2015 and 2018, eight cases of LSD-associated intoxication were identified at five acute hospitals in Hong Kong when LSD and its metabolites were detected in patient urine samples. Details of these eight patients (7 male, 1 female; age range, $16-25$ years) are presented in the Table. The most common presentation of LSD intoxication in these patients was agitation (63\%), followed by erratic behaviour (50\%) and violent behaviour (38\%). Impaired level of consciousness (75\%) and apparent sympathomimetic toxidrome (75\%) were documented in most patients. History of LSD use was elicited in all cases. However, only four patients were willing to volunteer the sources of LSD: one bought LSD from the Internet, one obtained LSD at a party, and two obtained LSD from friends. The most common co-ingestant was cannabis, which was detected in three cases. Amphetamine and methamphetamine were detected in one case. In one patient, phenibut (3-phenyl-4-aminobutyric acid), a central nervous system depressant structurally related to gamma-aminobutyric acid, was detected. Two cases were complicated by rhabdomyolysis and one of them required intensive care unit admission. The clinical details of these two cases are presented below.

\section{Case 1}

A 25-year-old man who had a history of childhood asthma presented to Princess Margaret Hospital, Hong Kong, in September 2018 with agitation after sublingual use of LSD on a stamp at a party. At presentation, his Glasgow Coma Scale was 13/15 (E4, V4, M5). The patient's blood pressure was $116 / 80 \mathrm{~mm} \mathrm{Hg}$, heart rate was 150 beats per minute, body temperature was $39.2^{\circ} \mathrm{C}$, and pupil sizes were $5 \mathrm{~mm}$ bilaterally. Biochemical investigations showed a peak creatine kinase (CK) value of $6260 \mathrm{U} / \mathrm{L}$, and urine myoglobin was positive. The patient was intubated and treated with alkaline diuresis in the intensive care unit. The urine specimen was analysed in the Toxicology Reference Laboratory, where LSD, its metabolite (2-oxo-3-hydroxy-LSD), diazepam, nordiazepam, temazepam, midazolam and propofol were detected.

\section{Case 2}

An 18-year-old man who enjoyed good past health presented to United Christian Hospital, Hong Kong, in April 2016 with erratic behaviour after sublingual use of LSD on a stamp obtained from his friends. At presentation, his Glasgow Coma Scale was 13/15 (E4, V4, M5). The patient's blood pressure was $127 / 50 \mathrm{~mm} \mathrm{Hg}$, heart rate was 167 beats per minute, body temperature was $38.7^{\circ} \mathrm{C}$, and pupil sizes were $6 \mathrm{~mm}$ bilaterally. Biochemical investigations showed metabolic acidosis, a peak CK value of $14732 \mathrm{U} / \mathrm{L}$, and urine myoglobin was positive. In the urine specimen, LSD, its metabolite (2-oxo-3-hydroxyLSD), and lidocaine were detected.

\section{Discussion}

Classically described as a psychedelic or hallucinogenic agent, LSD is structurally similar to serotonin (5-hydroxytryptamine), an important neurotransmitter in the central nervous system. It acts as a serotonin receptor agonist in the central nervous system and may produce prominent visual hallucinations, audiovisual synaesthesia, and derealisation. Significant sympathomimetic stimulation has also been observed. ${ }^{2}$ The effects typically begin within 30 to 60 minutes, peak at around 2 hours and can last for up to 12 hours after intake. $^{2}$ These effects are consistent with the current findings that most patients presented with apparent sympathomimetic toxidrome, characterised by tachycardia, hypertension, mydriasis, and pyrexia.

There is a general impression promulgated over the Internet and by celebrities that LSD 
TABLE. Details of eight cases of LSD intoxication recorded in Hong Kong between 2015 and 2018

\begin{tabular}{|c|c|c|c|c|c|c|c|c|}
\hline Case & $\begin{array}{c}\text { Sex/age } \\
\text { (years) }\end{array}$ & Presentation & $\begin{array}{c}\text { GCS at } \\
\text { presentation }\end{array}$ & $\begin{array}{c}\text { Prominent } \\
\text { sympathomimetic } \\
\text { toxidrome }\end{array}$ & Complication & $\begin{array}{l}\text { Source of } \\
\text { LSD }\end{array}$ & $\begin{array}{l}\text { Other DOA detected } \\
\text { (medications } \\
\text { administered were } \\
\text { not included) }\end{array}$ & $\begin{array}{c}\text { Date of } \\
\text { presentation }\end{array}$ \\
\hline 1 & $\mathrm{M} / 25$ & Agitation & 13 & Yes & Rhabdomyolysis & Party & Nil & Sep 2018 \\
\hline 2 & $M / 16$ & $\begin{array}{c}\text { Agitation } \\
\text { Erratic behaviour }\end{array}$ & 12 & Yes & Nil & Internet & Phenibut & Aug 2018 \\
\hline 3 & $\mathrm{M} / 17$ & $\begin{array}{c}\text { Agitation } \\
\text { Violent behaviour }\end{array}$ & 12 & No & Nil & Unknown & Cannabis & Jul 2018 \\
\hline 4 & $F / 21$ & $\begin{array}{c}\text { Agitation } \\
\text { Violent behaviour }\end{array}$ & 15 & No & Nil & Unknown & $\begin{array}{c}\text { Amphetamine } \\
\text { Methamphetamine }\end{array}$ & Aug 2017 \\
\hline 5 & $M / 21$ & Violent behaviour & 15 & Yes & Nil & Unknown & Nil & Jan 2017 \\
\hline 6 & $\mathrm{M} / 20$ & Erratic behaviour & 13 & Yes & Nil & Friends & Cannabis & Dec 2016 \\
\hline 7 & $\mathrm{M} / 18$ & Erratic behaviour & 13 & Yes & Rhabdomyolysis & Friends & Nil & Apr 2016 \\
\hline 8 & $\mathrm{M} / 17$ & $\begin{array}{c}\text { Agitation } \\
\text { Erratic behaviour }\end{array}$ & 14 & Yes & Nil & Unknown & Cannabis & Mar 2015 \\
\hline
\end{tabular}

Abbreviations: DOA = drugs of abuse; GCS = Glasgow Coma Scale; LSD = lysergic acid diethylamide

is harmless and even beneficial to personal development. Recently, LSD has re-emerged as a micro-dosing psychedelic. People consume regular low doses of LSD in an attempt to boost their creativity. ${ }^{3}$ However, this practice, also described as the Silicon Valley trend, lacks scientific evidence. These factors appear to have misled the public into underestimating the potential sequelae of LSD abuse. In contrast, our case series clearly demonstrates that LSD intoxication is associated with severe sequelae. In both cases complicated with rhabdomyolysis, no other stimulant-class drugs of abuse were detected, including conventional and emerging drugs of abuse. ${ }^{4}$ No better alterative causes of rhabdomyolysis were identified from the medical or drug history and biochemical investigations; LSD intoxication was the major contributing factor to rhabdomyolysis in both cases. Other cases of LSDassociated rhabdomyolysis have been reported in the literature. ${ }^{5,6}$ Fortunately, all patients in our series recovered uneventfully. However, at least one fatal case has been reported elsewhere. ${ }^{7}$

Frontline clinicians should be aware that LSD has re-appeared, disguised as a "safe" drug of abuse associated with multiple local intoxication cases with severe sequelae including rhabdomyolysis. Thorough investigations and serial monitoring are required to detect complications. Urine toxicology is useful to confirm the exposure to drugs of abuse. However, owing to its high potency, the dosage of LSD taken is small (in micrograms) and urine levels may be very low. ${ }^{2}$ A sensitive analytical system is required to detect the presence of LSD and its metabolite. Public education on the dangers or LSD abuse, and effective regulatory control by the government sectors are recommended.

\section{Author contributions}

All authors had full access to the data, contributed to the study, approved the final version for publication, and take responsibility for its accuracy and integrity.

Concept or design of study: All authors.

Acquisition of data: All authors.

Analysis or interpretation of data: All authors.

Drafting of the article: C Li, MHY Tang, TWL Mak.

Critical revision for important intellectual content: All authors.

\section{Conflicts of interest}

All authors have disclosed no conflicts of interest.

\section{Funding/support}

This research received no specific grant from any funding agency in the public, commercial, or not-for-profit sectors.

\section{Ethics approval}

Ethics approval for this study was granted by the Hong Kong Hospital Authority Kowloon West Cluster Research Ethics Committee (Ref KW/EX-19-003). The Committee exempted the study group from obtaining patient consent.

\section{References}

1. Nichols DE, Grob CS. Is LSD toxic? Forensic Sci Int 2018;284:141-5.

2. Dolder PC, Schmid Y, Steuer AE, et al. Pharmacokinetics and pharmacodynamics of lysergic acid diethylamide in healthy subjects. Clin Pharmacokinet 2017;56:1219-30.

3. Anderson T, Petranker R, Rosenbaum D, et al. Microdosing psychedelics: personality, mental health, and creativity differences in microdosers. Psychopharmacology (Berl) 2019;236:731-40.

4. Tang M, Ching CK, Tse ML, et al. Surveillance of emerging drugs of abuse in Hong Kong: validation of an analytical 
tool. Hong Kong Med J 2015;21:114-23.

5. Mercieca J, Brown EA. Acute renal failure due to rhabdomyolysis associated with use of a straitjacket in lysergide intoxication. $\mathrm{Br}$ Med J (Clin Res Ed) $1984 ; 288: 1949-50$
6. Berrens Z, Lammers J, White C. Rhabdomyolysis after LSD ingestion. Psychosomatics 2010;51:356-356.e3.

7. Fysh RR, Oon MC, Robinson KN, Smith RN, White PC, Whitehouse MJ. A fatal poisoning with LSD. Forensic Sci Int 1985;28:109-13.

\section{Answers to CME Programme Hong Kong Medical Journal June 2019 issue}

Hong Kong Med J 2019;25:178-82

I. Faecal microbiota transplantation for treatment of recurrent or refractory Clostridioides difficile infection in Hong Kong
A
1. True
2. True
3. False
4. True
5. False
B
1. True
2. False
3. True
4. True
5. True

Hong Kong Med J 2019;25:216-21

II. Statins role in preventing contrast-induced acute kidney injury: a scoping review
A
1. False
2. False
3. False
4. True
5. True
B 1. True
2. False
3. True
4. False
5. True 